\title{
EFFECT OF PAIRED FORMATIVE ASSESSMENT ON STUDENTS' LEARNING
}

\author{
Nighat Arif, Qamar Zia*, Tahira Sadiq \\ Riphah Islamic International University, Rawalpindi Pakistan, *Combined Military Hospital Lahore/National University of Medical Sciences (NUMS) Pakistan
}

\begin{abstract}
Objective: To determine the effect of paired formative assessment on students' learning. Study Design: Quasi experimental study.

Place and Duration of Study: Islamic International Medical College Rawalpindi, from Jan 2018 to Jun 2018.

Methodology: A total of 160 students who attended otolaryngology module were included in the study. Randomized allocation was done by computerized software programme and students were divided into 2 groups i.e. experimental (group A) and control group (group B). Later on in group A, pairing of students was done by lottery method. Group A and B were dealt with paired and individual formative assessment respectively. Effectiveness of both methods of learning was calculated on the basis of academic scores obtained in tests consisting of 20 MCQs from predefined and taught syllabus. A $p$-value were obtained by applying independent sample t-test and considered statistically significant at 0.05 .

Results: Out of 160 participants, 94 (58.7\%) were females and 66 (41.3\%) were males. In individual testing phase mean scores of group A was $13.36 \pm 2.22$ and mean scores of group B was $13.24 \pm 2.5(p 0.861)$. In paired formative assessment phase, mean scores of group A was $16.70 \pm 1.94$ (CI 95\% 2.16-4.55) and mean of scores of group B was $13.40 \pm 2.23$ (CI 95\% 2.16-4.55) $p=0.001$.

Conclusion: The effectiveness of paired formative assessment. This method provides students a conducive environment to achieve learning objectives.
\end{abstract}

Keywords: Formative assessment, Formative feedback, Graduate education, Medical education.

\footnotetext{
This is an Open Access article distributed under the terms of the Creative Commons Attribution License (https://creativecommons.org/licenses/by-nc/4.0/), which permits unrestricted use, distribution, and reproduction in any medium, provided the original work is properly cited.
}

\section{INTRODUCTION}

Due to the rising pressure on the educational institutes to meet high accomplishment objectives, schools and universities have been executing rigid assessment platforms within their educational systems. Evaluation and assessment programs are a key to measure the growth towards meeting a learning target. Formative assessment is a planned development and should be assimilated during the course of learning cycle to regulate students' current instructional techniques ${ }^{1}$. It is an umbrella term used to promote students' learning by accomplishing key objective, understanding of learning objectives, exhibiting student's knowledge to the instructor, familiarizing them with the potential of summative assessment ${ }^{2,3}$.

In order to alter the delimited and inhibited forms of summative assessment, educators are now being enthused to place more importance on interactions in classroom learning, inspiring students to reflect and achieving a process of co-assessment in their knowledge 4 . To improve the learning bases of students, teachers should use students-centred tactics in their teaching 5 .

Formative assessment is a part of the develop-

Correspondence: Dr Qamar Zia, Department of Urology, Combined Military Hospital, Lahore Pakistan

Received: 19 Dec 2019; revised received: 26 Apr 2020; accepted: 28 Apr 2020 mental or on-going teaching learning process in which teachers take a positive approach and employ constructive communication techniques to provide guidance and continuous feedback to the students on their performance ${ }^{6}$. Paired formative assessment is a novel technique in which discussion and feedback process take place simultaneously amongst the students' pair, supervised by the teacher. Paired formative assessment is a potentially transformative instructional tool that aims to support learning. The growing interest of educational institutions to make students autonomous and lifelong learners, has motivated them to re-consider the association between learning and its assessment. We evaluated the effect paired formative assessment in this experimental study.

\section{METHODOLOGY}

Paired formative assessment was done at Islamic International Medical College Rawalpindi, from Jan to Jun 2018). The students of $3^{\text {rd }}$ year and $4^{\text {th }}$ year MBBS students participated in the study after approval of study by ethics review board (Riphah/ERC/18/0629). As the numbers of students in both $3^{\text {rd }}$ and $4^{\text {th }}$ year are 100 , therefore the accessible population for the study was 200 students who attended Otolaryngology module. The sample of students was taken by simple random sampling technique. The minimum sample size was 134 which was calculated using the software for 
sample size calculation. Clinical.com (statistic >> sample size calculator).

Randomized allocation was done by computerized software programme and students were divided into two groups i.e. experimental (group A) and control group (group B). Later on in group A, pairing of students was done by lottery method, after informed written consent. Students who did not attend tutorials of the pre-defined syllabus were excluded from the study.

All students were informed to come prepared for formative assessment. In the individual phase of assessment both groups were given a test consisting of 20 MCQs from predefined and taught syllabus. Time allotted for test was 30 minutes. Students were given 30 minutes break. Same MCQs were rearranged for formative assessment phase. Students of group A were randomly paired using lottery method. Group A and B were given test of rearranged MCQs. Time allotted was 30 minutes. Scores of group A and B in individual and formative assessment phases were compared. Statistical analysis was done using SPSS-23. All the data was entered in a specially designed proforma and Statistical analysis was performed by using SPSS 23. Mean \pm SD was calculated for quantitative variables. Frequency and percentage were calculated for qualitative variable.

Before assessment, students were cautioned that pairing was not to promote cheating. Instead, it was intended to help everybody to learn. Teachers gave students enough time for discussion with partners as this made learning more meaningful.

\section{RESULTS}

The descriptive analysis presented in table-I below showed that out of 160 study sample, 94 (58.7\%) were the females and $66(41.3 \%)$ were the males.

In individual testing phase mean scores of group A was $13.36 \pm 2.22$ and mean scores of group B was $13.24 \pm 2.5(p=0.861)$. In formative assessment phase, mean scores of group A was $16.70 \pm 1.94$ (CI 95\% 2.16$4.55)$ and mean of scores of group B was $13.40 \pm 2.23$ (CI 95\% 2.16-4.55) ( $p=0.001)$.

Paired formative assessments of experimental group showed high association between post-test marks and students learning. Students got maximum marks after pairing.

The averages of the paired assessment and individual test marks also indicated that the participants obtained higher marks in the paired formative assess- ment than in the individual. Here we concluded that our hypothesis was true. Students performed better in paired formative assessment phase.

Table-I: Total study population and its gender distribution.

\begin{tabular}{l|c|c}
\hline \multicolumn{3}{|c}{ Statistics } \\
\hline Gender & Number & Percentage (\%) \\
\hline Male & 66 & 41.3 \\
\hline Female & 94 & 58.7 \\
\hline
\end{tabular}

Table-II: Independent t-test between scores of individual and formative phase of group $A$.

\begin{tabular}{c|c|c|c}
\multicolumn{2}{c|}{ Group \& Assessment type } & Mean Score & $\boldsymbol{p}$-value \\
\hline \multirow{2}{*}{$\mathrm{A}$} & Individual & $13.36 \pm 2.23$ & \multirow{2}{*}{0.001} \\
\cline { 2 - 3 } & Formative & $16.70 \pm 1.94$ & \\
\hline
\end{tabular}

\section{DISCUSSION}

This study on paired formative assessment was unique and directed on medical college students in Islamic International medical college, where the conservative or traditional individual formative assessment was frequently used.

Medical education is a dynamic process and its methods are constantly changing to achieve new learning objectives ${ }^{7}$. Student's centred methods are evolving to foster their learning and performance ${ }^{8}$. Assessment scores improve by involving students into discussion and formative process of feedback ${ }^{9}$.

The growing need of progress of new assessment forms such as self, peer and co-assessment is anobligation to create future independent reflective practitioner ${ }^{6}$. Paired formative assessment is a new tactic. This study examined pair work from a new viewpoint such that its main impact is the students' learning. The union was put into its place to encourage students to learn from each other through communication. Thus, new knowledge can be combined and understood through collaborating social processes. The main goal of this research was to scrutinise the manner in which the 'peer interaction' is operationalized in a pair format task and to use this as the foundation for the expansion of Paired formative assessment ${ }^{7}$. The Appalachian education laboratory promotes active involvement of students in their own learning and paired formative assessment gives an excellent chance to achieve this goal $^{10}$. This study arose from anapplied need to encourage students for formative assessment for making their interface in a paired task in a non-threatening environment.

In peer learning, students build and negotiate their own connotation and understanding of content and perception ${ }^{8,9}$. Involving the same concept with pair 
work during assessment, students were involved in searching for, collecting, analysing, interrogating and applying information to complete an assignment or solve a problem ${ }^{10}$. This research project was established on the work of Panadero et al who employed similar pre-test and post-test to examine the effective strategies of co-operative learning to determine the learning outcomes ${ }^{11,12}$. These studies concluded that cooperative strategies used in the formative assessment improved students' who were revealed to paired strategies were able to achieve a higher score as compared to the ones included in controlled group which had completed task individually as an old-custom strategy 13,14 .

Johnson and Johnson conducted 117 studies and observed the effects of competitive, individualistic and co-operative strategies on academic achievement ad established strong co-relation between co-operative paired learning than individualistic learning ${ }^{15,16}$.

The main focus of our research was to explore the effectiveness of social interactions during assessment. Knowledge sharing/transfer is the main advantage of pair programming as reported in literature and our study results also confirm this finding that knowledge transfer/sharing is improved in pairing as compared to individual assessment ${ }^{17}$. This study was supported by the study which incorporated the idea of buddy quiz $^{18}$. This approachrefers to a student assigned to another as a partner during quizzes, the two students or buddies are allowed to freely discuss and process information collaboratively about an item in a quiz. Exchanges led to an overall increase in participation, motivation and ultimately improve learning of the class ${ }^{19}$.

In paired formative assessment the foremost key component is positive interdependence among paired students, so they understand that they linked together for a purpose that one cannot achieve success unless they both synchronize their efforts to accomplish the goal. Johnson (2016) noted positive interaction in pairs, providing each other the needed help, sharing concepts, challenging other's conclusion and reasoning the order to promote high order thinking to solve problem issues; and working constructively together to accomplish their mutual goal ${ }^{20}$. These results support the hypothesis that paired formative assessment has an overall positive effect of improving the academic performance of students.

This study was a timely endeavour in present time of medical education reforms. Paired formative assessment proved to be a helpful arrangement for learners to be benefited by the quality of performance of other equal-status learners, because of the favourable and non-threatening environment.

\section{Implications for Future Research}

Firstly, future research need to look at other colleges in Pakistan, which have different settings and are located in different environments to determine the implication of paired formative assessment on the performance of students.

Secondly, future studies should be emphasized on the long-term impact of paired formative assessment on students' performance.

Thirdly, this study was conducted on students' academic performance only. The researchers expect that paired formative assessment impacts other variables. Additionally, future studies should examine how a paired formative assessment affects the productivity and impact on students' motivation.

Lastly, future researches can also find the perception of students regarding paired formative assessment strategy. This can be done by looking at their participation, performance, enjoyment during assessment and challenges they face using paired strategies.

\section{Disclosure}

One of the author was working in Rawalpindi during the period of this study and is currently posted to Combined Military Hospital Lahore.

\section{CONCLUSION}

The practice of paired formative assessment seems to have positive impact on students learning. The results of our study showed that structured paired formative assessment in the class-room is a student centred instructions to maximize students' participation, sharing of knowledge, and enhanced learning and ultimately improve academic performance.

\section{CONFLICT OF INTEREST}

This study has no conflict of interest to be declared by any author.

\section{REFERENCES}

1. Gillies RM. Cooperative learning: review of research and practice. Aust J Teach Edu 2016; 41(3): 3-5.

2. Andradre H, Brookhart SM. In: The role of classroom assessment in supporting self-regulated learning. Paper presented at the assessment for leaning: meeting the challenge of implementation. March 2016.

3. Hawe E, Dixon H. Assessment for learning: a catalyst for student self-regulation. Assess Eval High Edu 2017; 42(8): 1181-92.

4. Soderstrom, NC, Bjork, RA. Learning versus performance: An integrative review. Perspect Psychol Sci 2016; 10(2): 176-99. 
5. Gronlund NE. Assessment of student achievement. $7^{\text {th }}$ ed. Boston: Allyn and Bacon; 2003.

6. Ahmad RN, Bhatti MM, Khan AH, Ghayur S, Rafi S, Naseem S, et al. Small group discussion as a learning strategy for medical undergraduates. Rawal Med J 2014; 39(3): 344-48.

7. Spencer JA, Jordon RK. Learner centred approaches in medical education. Br Med J 1999; 318(7193): 1280-83.

8. Ramzan M, Mushtaq R, Ansar A, Bibi A, Sabah S, Mughal A, et al. Effects of teaching methods on assessment outcomes. Biomedica 2015; 31(3): 209-14.

9. Bakhtiar U, Awan AS, Shahdab N. Role of unseen pretest formative assessment in improving clinical interest and final scores of final year students. Rawal Med J 2013; 38(4): 440-43.

10. Panadero, E. A review of self-regulated learning: six models and four directions for research. Front Psychol 2017; 8(2): 422-23.

11. Baas D, Castelijns J, Vermeulen M, Martens BR, Segers M. The relation between Assessment for Learning and elementary students' cognitive and metacognitive strategy use. Br J Edu Psychol 2015; 85(1): 33-46.

12. Rachmah DN. Effects of jigsaw leaning learning method on students' self-efficacy and motivation to learn. J Edu Health Community Psychol 2017; 6(3): 1-9.

13. Dinsmore DL, Wilson HE. Student participation in assessment: does it influence self-regulation? Handbook of human and social factors in assessment. $2^{\text {nd }}$ ed 2016: 145-68.

14. Panadero E, Andrade H, Brookhart S. Fusing self-regulated learning and formative assessment: a roadmap of where we got here, and where we are going? Aust Edu Res 2018; 45(1): 13-31.

15. Tandog VSJ, Pafrcutilo JO. A pair assessment and its influence on students 'performance in calculus and in mathematics and test anxiety.international conference in science and mathematics education. Up Nis Med 2010; 61(6): 55-58.

16. Tay HY. Setting formative assessment real-world contexts to facilitate self-regulated learning. Edu Res for Policy Prac 2015; 14(2): 169-87.

17. Panuel WR. Shepard LA. Social models of learning and assessment. The Wiley handbook of cognition and assessment: Frameworks, methodologies, and application, 2017; 34(2): 146-73.

18. Rushton A. Formative assessment: a key to deep leaning? Medical Teacher 2005; 27(6): 509-13.

19. Johnson A. The implementations ad evaluation of formative feedback on students' attitudes and perceptions on their learning: An action research. Capella University. 2016.

20. Zakaria E, Solfitri T, Daud Y, Abidin Z. Effect of cooperative learning on secondary school students' mathematic achievement. Creative Educ 2013; 4(02): 98. 